\title{
LDPE-Based Blends and Films Stabilized with Nonreleasing Polymeric Antioxidants for Safer Food Packaging
}

\author{
L. Boragno, ${ }^{1}$ P. Stagnaro, ${ }^{1}$ S. Losio, ${ }^{2}$ M. C. Sacchi, ${ }^{2}$ S. Menichetti, ${ }^{3}$ C. Viglianisi, ${ }^{3}$ \\ L. Piergiovanni, ${ }^{4}$ S. Limbo \\ ${ }^{1}$ Istituto per lo Studio delle Macromolecole ISMAC-CNR, 16149 Genova, Italy \\ ${ }^{2}$ Istituto per lo Studio delle Macromolecole ISMAC-CNR, 20133 Milano, Italy \\ ${ }^{3}$ Dipartimento di Chimica "U. Schiff", Università di Firenze, 50019 Sesto Fiorentino (FI), Italy \\ ${ }^{4}$ Dipartimento di Scienze e Tecnologie' Alimentari e Microbiologiche, Università degli Studi di Milano, \\ 20133, Milano, Italy
}

Received 8 September 2010; accepted 21 August 2011

DOI 10.1002/app.35516

Published online 27 November 2011 in Wiley Online Library (wileyonlinelibrary.com).

\begin{abstract}
Several novel random copolymers of ethylene and 1-olefin counits bearing a highly efficient phenolic antioxidant moiety placed at different distances from the polymerizable double bond were prepared in the presence of a metallocene catalyst. These copolymers were meltblended with an antioxidant-free LDPE in an internal batch mixer to obtain innovative materials containing nonreleasing polymeric antioxidants suitable for safer food packaging applications. Blends and films, obtained by compression molding, were tested for their thermal and thermo-oxidative stability by thermogravimetric analysis both in dynamic and isothermal conditions. Films containing the macromolecular antioxidants showed a longer
\end{abstract}

induction time before $\mathrm{O}_{2}$ uptake starts and, consequently, a higher degradation temperature than neat LDPE or LDPE containing a low molecular weight commercial additive. Aging tests demonstrated that the new polymeric antioxidants also exert a valid protection against photo-oxidation. Eventually, migration tests demonstrated the absence of any trace of products containing the antioxidant moiety when the films were kept in contact with a food simulant. (c) 2011 Wiley Periodicals, Inc. J Appl Polym Sci 124: 3912-3920, 2012

Key words: blends; nonreleasing food packaging; polyethylene (PE); polymeric antioxidants; thermogravimetric analysis (TGA)

\section{INTRODUCTION}

Aerobic organisms use molecular oxygen as the primary source of energy liberated with oxidation of nutrients. Nevertheless, living in the presence of such an oxidizing agent has required the development, during evolution, of a number of proper defense mechanisms either endogenous or exogenous. Among the former, the drastic reduction of oxygen partial pressure moving from the body surface to the internal tissues and a panel of enzymes (superoxide dismutase, catalase, peroxidases, etc.) able to keep the concentration of reactive oxygen species under control, are the more relevant. The assumption, with the diet, of small molecules with antioxidant activity (flavonoids or vitamin $\mathrm{P}$, tocopherols or vitamin $E$, ascorbic acid or vitamin $C, \beta$ carotene or vitamin $\mathrm{A}$, etc.) represents the actual ex-

Correspondence to: P. Stagnaro (stagnaro@ge.ismac.cnr.it). Contract grant sponsor: CARIPLO Bank Foundation.

Journal of Applied Polymer Science, Vol. 124, 3912-3920 (2012) (c) 2011 Wiley Periodicals, Inc. ogenous defense. Such antioxidant arsenal is commonly associated with a healthy and long life. ${ }^{1}$

All synthetic polymers, which during the last decades have been increasingly applied in packaging, building, automotive, electrical, and electronic fields, have also to face the presence of molecular oxygen and often suffer because of oxidation and oxidative degradation that can severely modify the structure and the function of manufactures. Indeed, the protection of materials against oxidation is an unavoidable ordinary practice. ${ }^{2}$

Commercial polyolefins, the most common foodcontact materials, are usually stabilized by meltblending with antioxidant additives, known as free radical scavengers, to inhibit or retard degradation. Unfortunately, the vast majority of commercial antioxidants are low molecular weight molecules more polar than the polyolefin matrices. Inevitably, both these characteristics facilitate their migration into the neighboring matter. Problems due to migration as well as to volatility and extractability of antioxidants from plastics become more serious when food packaging is involved, since the releasing of the additives occurs into edible goods with possible organoleptic changes and/or risk of toxicity. ${ }^{3}$ For this reason, the 
possibility of maintaining a higher level of antioxidant protection with limited or no risk of additive migration is an appealing characteristic for an ideal food packaging material.

Since the early sixties, efforts have been made to solve the problems due to migration or extractability of stabilizers by chemically linking antioxidant additives to the polymeric matrix. ${ }^{4}$ A challenging approach to this matter consists in copolymerization of the commonly used $\alpha$-olefins (e.g., ethylene or propylene) with a monomer bearing the stabilizing group. Preparative methods that produced molecules having both a polymerizable group and a hindered phenol moiety to be used as antioxidant comonomers were developed since the late sixties. ${ }^{5-}$ 13 However, the poor incorporation of the bulky comonomers with traditional Ziegler-Natta catalytic systems and the decrease of catalytic activity due to catalyst poisoning by polar comonomers were detrimental to the application of such polymerization processes.

More recently, Wilén and Nasman reported the successful copolymerization of ethylene and propylene with comonomers bearing an antioxidant phenolic moiety carried out by using the newly discovered, more ductile metallocene catalysts. ${ }^{14,15}$ However, even this new process has been, so far, of limited practical use since most of the commercial polyolefin materials are still produced with traditional heterogeneous Ziegler-Natta catalysts, only capable of incorporating linear conventional comonomers.

In an attempt to overcome the synthetic difficulties and the technical obstacles for an industrial application of the abovementioned procedures, we have adopted an approach that takes advantage of the wide synthetic capability of metallocene catalysts of producing ethylene-based copolymers with controlled amounts of an efficient stabilizing comonomer, to be used as "masterbatches" in the meltblending with commercially available polyolefinic matrices. Recently, we reported the preparation of olefinic comonomers [Scheme 1(a)] bearing a highly efficient antioxidant additive similar to 2,6-di- $t$ butyl-4-methoxyphenol (BHA), and capable of easily copolymerizing in variable and tunable amount with ethylene to give random copolymers. ${ }^{16,17}$

In the present work, we report the melt-blending of such copolymers [Scheme 1(b)] with an additivefree commercial LDPE matrix to obtain blends containing covalently bonded antioxidant moieties in concentration comparable to that typically used for the low molecular weight antioxidants. The effectiveness of this new family of polymeric additives in protecting the polyolefinic matrix is also described. Films obtained by compression molding of the abovementioned blends were analyzed in terms of
(A)

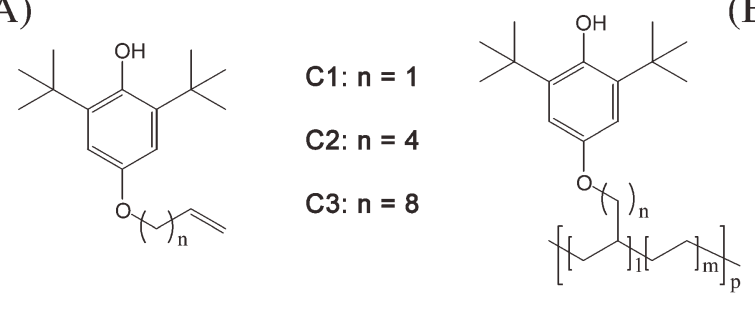

(B)
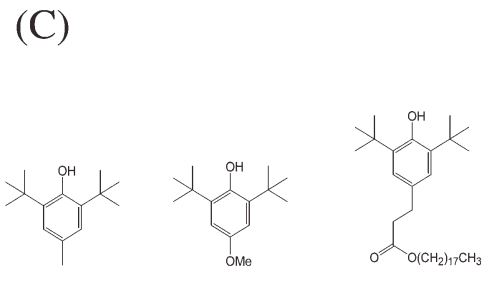

A.O. 1076

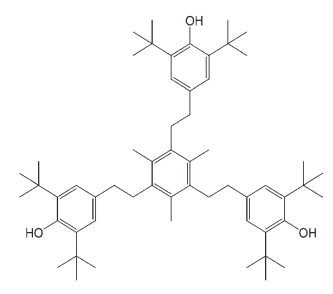

A.O. 1330

Scheme 1 (A) Comonomers used in this study; (B) Structure of the copolymers EC1, EC4, and EC8 with $n=1,4$, and 8 , respectively; (C) Typical phenolic antioxidants used for protecting plastics.

thermal, thermo-oxidative, and photo-stability and compared with LDPE films containing the traditional BHA additive. Investigations on the nonreleasing character of these macromolecular additives are reported as well.

\section{EXPERIMENTAL}

\section{Materials}

Random copolymers of ethylene with 4-allyloxy-2,6di-t-butylphenol $(\mathbf{C} \mathbf{1}, n=1)$, 4-hexa-5-enyloxy-2,6-di$t$-butylphenol $(\mathrm{C} 4, n=4)$, and 4-dec-9-enyloxy-2,6di-t-butylphenol $(\mathbf{C} 8, n=8)$, in the following labeled EC1, EC4, and EC8 respectively, were synthesized and thoroughly characterized as described in Refs. 16 and 17. Their general structure is sketched in Scheme 1 (b) and their main features are summarized in Table I. The additive-free commercial LDPE (Lupolen LP 2420F), used as polymer matrix, was kindly supplied by Lyondelbasell Italia (Ferrara, Italy). 2,6Di-t-butyl-4-methoxyphenol (butylhydroxy anisole, BHA), 2,6-di-t-butyl-4-methylphenol (butylhydroxy toluene, BHT), and 2,2,4-trimethylpentane (isooctane) were purchased from Sigma Aldrich (Italy).

\section{Blends and films}

Blends of the additive-free LDPE and the synthesized copolymers were prepared by melt-blending in an internal batch mixer (Brabender Plasti-Corder ${ }^{\circledR}$ ) operating at $130^{\circ} \mathrm{C}$ and $50 \mathrm{rpm}$ for 15 min under $\mathrm{N}_{2}$. To have $500 \mathrm{ppm}$ of antioxidant moieties dispersed into the polyethylene matrix, a proper amount of copolymer was used for each blend, taking into account the specific copolymer composition. The 
TABLE I

Microstructural, Molecular, and Thermal Properties of EC1, EC4, and EC8 Copolymers Obtained by rac-(EBTHI)ZrCl 2 and MAO As Catalytic System ${ }^{16}$

\begin{tabular}{lccccccc}
\hline Sample $^{\mathrm{a}}$ & $\begin{array}{c}\text { Comonomer } \\
\text { content }^{\mathrm{b}}(\mathrm{mol} \%)\end{array}$ & $\mathrm{M}_{\mathrm{n}}{ }^{\mathrm{c}}$ & $\mathrm{M}_{\mathrm{w}} / \mathrm{M}_{\mathrm{n}}{ }^{\mathrm{c}}$ & $T_{c}{ }^{\mathrm{d}}\left({ }^{\circ} \mathrm{C}\right)$ & $\Delta H_{c}{ }^{\mathrm{d}}(\mathrm{J} / \mathrm{g})$ & $T_{m}{ }^{\mathrm{d}}\left({ }^{\circ} \mathrm{C}\right)$ & $\Delta H_{m}{ }^{\mathrm{d}}(\mathrm{J} / \mathrm{g})$ \\
\hline EC1 & 1.0 & 21,000 & 2.8 & 109 & 164 & 127 \\
EC4 & 0.55 & 26,000 & 2.8 & 114 & 191 & 129 & 167 \\
EC8 & 1.0 & 11,000 & 2.4 & 107 & 162 & 123 & 168 \\
\hline
\end{tabular}

${ }^{\text {a }}$ Copolymerization conditions: solvent $=$ toluene, total volume $=50 \mathrm{~mL}$, catalyst $=5 \mu \mathrm{mol}, \mathrm{Al} / \mathrm{Zr}=1500(\mathrm{~mol} / \mathrm{mol}$ ), $t_{\mathrm{pol}}=30 \mathrm{~min}, \mathrm{~T}=35^{\circ} \mathrm{C}, P_{\text {ethylene }}=0.3 \mathrm{~atm}$, comonomer $=1 \mathrm{mmol}$, TIBA (tri-iso-butylaluminum) $/ \mathrm{comonomer}=2(\mathrm{~mol} /$ mol), [ethylene]/[comonomer] $=1.75$.

$\mathrm{b}$ Determined by ${ }^{13} \mathrm{C}$ NMR.

${ }^{c} M_{n}$ and $M_{w} / M_{n}$ determined by SEC.

d Determined by DSC on cooling $\left(T_{c}, \Delta H_{c}\right)$ and second heating $\left(T_{m}, \Delta H_{m}\right)$.

value of $500 \mathrm{ppm}$ was chosen because it is a typical amount of antioxidant added to stabilize polyolefinic materials. Neat LDPE and its mixture with 500 ppm of commercial BHA antioxidant were treated under identical processing conditions and used for reference purposes.

To improve experimental data reproducibility and reliability, $120 \pm 15 \mu \mathrm{m}$ thick films were obtained from the blends by compression molding at $130^{\circ} \mathrm{C}$. Films ensure correct sampling for thermogravimetric analysis (TGA) experiments and successive aging and migration tests.

\section{TGA analysis}

Thermal and thermo-oxidative stabilities were tested by TGA under $\mathrm{N}_{2}$ and $\mathrm{O}_{2}$ atmosphere, respectively, using a PerkinElmer TGA7 instrument on blends and/or films. TGA measurements were carried out both in dynamic (heating rate $20^{\circ} \mathrm{C} / \mathrm{min}$ ) and isothermal conditions. In the dynamic mode, the explored temperature range was $50-700^{\circ} \mathrm{C}$. Isothermal experiments were carried out by rapidly reaching $180^{\circ} \mathrm{C}$ under $\mathrm{N}_{2}$ atmosphere; after $10 \mathrm{~min}$ the purge gas was switched to oxygen to start the oxygen induction time (OIT) measurement $\left(t_{0}\right.$ refers to the moment in which oxygen enters the instrument furnace). To guarantee the comparison and reproducibility of the OIT experimental results, the isothermal measurements were carried out on film specimens with the same weight and the same surface area exposed to the oxygen action.

\section{Aging tests}

Squarely cut films $(2.5 \times 2.5 \mathrm{~cm})$ were placed in $22-$ $\mathrm{mL}$ glass vials (one specimen each vial, with the help of a thin metal rod) filled with a modified atmosphere $(60 \%$ oxygen and $40 \%$ nitrogen) created by using an automatic packaging machine (Tecnovac S100 DGT gas) connected to a gas mixer (PBI Dansensor MAP mix 9000). The vials were then hermeti- cally closed and stored horizontally on a black turning plate inside a thermostated and ventilated black cabinet for 21 days. During storage, the samples were exposed to constant illumination produced by a $300 \mathrm{~W}$ Osram-Ultra Vitalux ${ }^{\circledR}$ lamp simulating the sun light. The sample temperature recorded by means of data loggers (Smart Reader SR04), was $50^{\circ} \mathrm{C} \pm 2^{\circ} \mathrm{C}$. The lamp was placed $20 \mathrm{~cm}$ above the rotating samples with incident beam at $90^{\circ}$. Irradiance at samples level was measured using a portable digital photoradiometer (Delta Ohm HD2102.2) equipped with specific probes. The irradiance recorded values were: $204 \pm 35,11 \pm 1$, and $12 \pm 3$ $\mathrm{W} / \mathrm{m}^{2}$ in the visible, UVA, and UVB regions, respectively. Head space gas inside the vials was periodically sampled taking $20 \mu \mathrm{L}$ of gas with a gas tight syringe; the gas was not restored after sampling. $\mathrm{O}_{2}$ concentration was analyzed by a gas chromatograph (Hewlett-Packard HP 5890 series II) equipped with a thermoconductivity detector and a steel column (2 $\mathrm{m} \times 6 \mathrm{~mm}$ CTR I Alltech, Milano, Italy). Oxygen uptake was determined by analysis of the gas phase as indicated by Gijsman et al. ${ }^{18}$

Fourier transform infrared spectroscopy was performed on films at different storage times using a FT-MIR (Spectrum 100, PerkinElmer) in normal transmission mode (32 scans, resolution $4 \mathrm{~cm}^{-1}$, wave number range $4000-400 \mathrm{~cm}^{-1}$ ) to monitor the evolution of carbonyl, vinyl, and hydroxyl groups as described by Yang et al. ${ }^{19}$

\section{Specific migration test}

A specific migration test was carried out using the total immersion procedure with a ratio of $1 \mathrm{dm}^{2}$ of food contact area to $100 \mathrm{~mL}$ of a fatty food simulant (isooctane). A temperature of $20^{\circ} \mathrm{C} \pm 1{ }^{\circ} \mathrm{C}$ and a time of 2 days were chosen as test conditions related to the condition of general use (EN 13130-1:2004). ${ }^{20}$ After the contact time elapsed, the simulant was added with an internal standard (BHT) and the resultant mixture dried at $55^{\circ} \mathrm{C}$ in a rotary evaporator. The 
residue was dissolved in $2 \mathrm{~mL}$ of $n$-hexane and the chromatographic analysis was carried out with a PerkinElmer gas chromatograph (AutoSystem XL), equipped with a programmable injector maintained at $250^{\circ} \mathrm{C}$. Samples $(1 \mu \mathrm{L})$ were injected in splitless mode. A DB-5MS (Agilent Technologies, Milano, Italy) capillary column $(30 \mathrm{~m} \times 0.25 \mathrm{~mm}$ i.d., film thickness $0.25 \mu \mathrm{m}$ ) was used with the following heating program: the initial temperature of $60^{\circ} \mathrm{C}$ was held for $2 \mathrm{~min}$, then increased at a rate of $10^{\circ} \mathrm{C} / \mathrm{min}$ to $250^{\circ} \mathrm{C}$ and at a rate of $20^{\circ} \mathrm{C} / \mathrm{min}$ up to $280^{\circ} \mathrm{C}$ and held for $5 \mathrm{~min}$ at the final temperature. UHP helium was used as carrier gas at a flow rate of $1.0 \mathrm{~mL} /$ min. The gas chromatograph was interfaced to a PerkinElmer TurboMass quadrupole mass spectrometer with an electron impact ion source detector operating at $70 \mathrm{eV}$ in full scan (40-550 amu) or in selected ion monitoring mode. The temperature of the quadrupole was $200^{\circ} \mathrm{C}$ and that of the ion source $230^{\circ} \mathrm{C}$.

To determine the linearity of BHA response, a series of standard solution containing from 0.100 up to 40.0 micrograms/L of the analyte was tested. Plotting the peak area obtained for each concentration against the concentration a linear regression of 0.995 was found. The limit of detection was evaluated on the basis of a signal-to-noise ratio of 3 and estimated equal to $3.2 \mu \mathrm{g} / \mathrm{L}$.

\section{RESULTS AND DISCUSSION}

Low molecular weight hindered phenols [Scheme 1(c)] are common chain-breaking antioxidants, used for protecting plastics against thermal oxidation and discoloring occurring during processing, as well as on long-term aging. ${ }^{2}$

Apart from the intrinsic stabilizing activity of hindered phenols, other factors play an important role in designing a good stabilizer. In fact, an antioxidant should be chemically able to interfere with the oxidation reactions, and should resist its own degradation during film manufacturing as well as its loss by migration to the matrix surface and subsequent possible contamination of the contact matter. ${ }^{21}$ This point is of particular relevance in the case of additives for plastics used for food packaging. ${ }^{22-24}$ Indeed, European legislation regulates migration from food-contact materials, such as packaging, into foods by an overall migration limit applicable to the total of the migrating material and specific migration limits referring to individual substances or groups of substances. $^{24}$

The compatibility of the additive with the polymer must ensure a good dispersion of the stabilizer into the matrix and a reduced rate of diffusion toward the surface of the matrix, where the additive can be physically lost. To fulfill such properties, we have tackled a work aimed at preparing polymeric addi- tives bearing covalently bonded highly efficient antioxidant pendant groups. In previous articles, we reported on design and syntheses that led to the exploitation of novel comonomers bearing a phenol antioxidant moiety analogous of BHA, placed at different distances from the olefinic polymerizable double bond [Scheme 1(a)]. Said comonomers copolymerize with ethylene in the presence of selected methylaluminoxane-activated metallocene catalysts, such as rac-ethylenebis(tetrahydroindenyl)zirconium dichloride (rac-(EBTHI) $\mathrm{ZrCl}_{2}$ ), to produce ethylenebased random copolymers with tunable antioxidant group concentration as well as molecular weight and molecular weight distribution. ${ }^{16,17}$

Among those synthesized with EBTHI catalyst, three copolymers, labeled EC1, EC4, and EC8, with 1,4 , and 8 methylenic units, respectively, separating the pendant phenolic ring from the polymer backbone were selected [Scheme 1(b)]. These copolymers presented the lowest and more similar molar content of comonomer counits. The comonomer contents along with molecular and thermal properties of the selected copolymers are shown in Table I.

The copolymers were melt-blended in an internal batch mixer with an antioxidant-free commercial LDPE matrix as described in the experimental section. To have blends with an antioxidant moiety content of $500 \mathrm{ppm}$, which corresponds to a typical amount of BHA added for stabilizing polyolefins, proper amounts of copolymers were used, taking into account for each copolymer the actual content of counits bearing the phenolic moiety. The effect of melt-blending on the mechanical and optical properties of the films (being the latter of primary importance since the consumers "want" to see the food inside the packaging) is expected to be negligible. Indeed, the antioxidant copolymers are mixed in quantities of around $1 \mathrm{wt} \%$; such low amount of a compatible additive does not appreciably affect the matrix properties. To ensure correct sampling TGA experiments and successive aging and migration tests, film samples were obtained from the abovementioned blends by compression molding at $130^{\circ} \mathrm{C}$.

\section{Thermal and thermo-oxidative stability studies}

\section{Dynamic TGA}

Thermal and thermo-oxidative stability of the blends of the polymeric additives with the antioxidant-free LDPE matrix was first investigated by TGA, carried out in dynamic mode conditions both under nitrogen and oxygen atmosphere.

As expected, in nitrogen atmosphere no appreciable differences in the degradation onset temperature were observed among LDPE samples containing no additive, $500 \mathrm{ppm}$ of $\mathrm{BHA}$ or the proper amount 


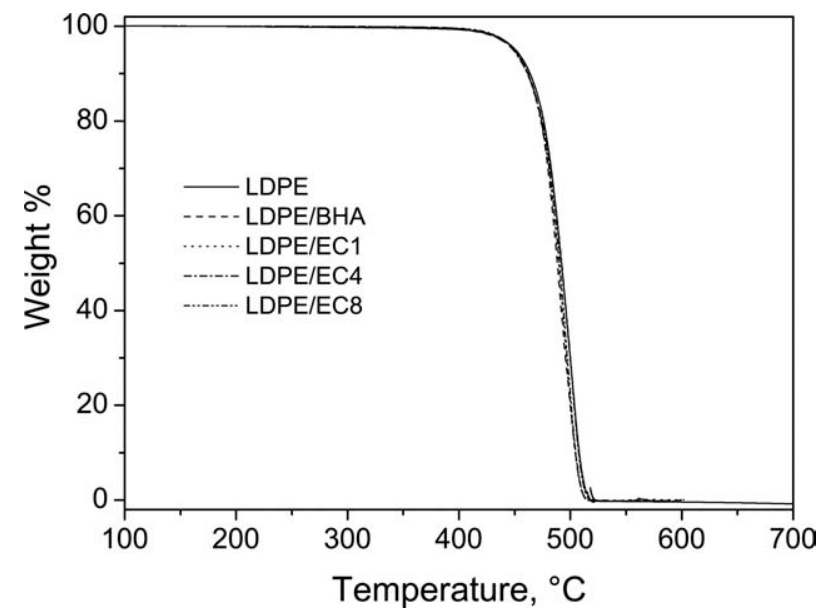

Figure 1 Dynamic TGA curves under $\mathrm{N}_{2}$ (heating rate $20^{\circ} \mathrm{C} / \mathrm{min}$ ) of LDPE blends containing the polymeric antioxidants. Neat LDPE and LDPE containing an equivalent amount of BHA are also reported for comparison.

of polymeric antioxidants, being this value around $415^{\circ} \mathrm{C}$ in any case (Fig. 1).

Analogous dynamic TGA experiments carried out in oxidative atmosphere constituted by pure oxygen showed that for blends containing the polymeric nonreleasing antioxidants, the degradation process takes place later compared to that observed for the neat LDPE sample and the blend with traditional BHA antioxidant (Fig. 2); indeed, as clearly evident from Figure 2(A), both $\mathrm{T}_{\mathrm{D} 20}$ and $\mathrm{T}_{\mathrm{D} 50}$ values (temperatures at which the sample weight loss is equal to 20 and $50 \%$, respectively) are shifted at temperatures $40-50^{\circ} \mathrm{C}$ higher with respect to those observed for neat LDPE and BHA-additivated samples.

On the other hand, the $\mathrm{O}_{2}$ uptake entity is quite similar for all the samples, as one can see from the expanded region of the abovementioned TGA profiles reported in Figure 2(B). In particular, the highest weight increase due to oxygen uptake occurs for the antioxidant-free LDPE, in which, moreover, the uptake itself (i.e., the degradation process) begins at the lowest temperature. The highest temperature for the onset of the oxygen uptake, together with the lowest amount of oxygen incorporation was shown by sample LDPE/EC4 containing the polymeric antioxidant with four methylenic units as spacer.

The behavior of the different samples could be explained on the base of the role played by the spacer taking into account: (i) the antioxidant moiety mobility, which increases on increasing the spacer length and (ii) the presence, in the correspondence of the comonomer branches along the polymer main chain, of tertiary carbons, which constitute weak points for the formation of radicals during the thermo-oxidative process. For the shortest spacer (one $\mathrm{CH}_{2}$ ), the mobility is the lowest and the antioxidant action is limited by the small volume the phenol moiety can explore; on the other hand, it can exert an efficient steric protection on the abovementioned tertiary carbon. In the case of the longest spacer (eight $\mathrm{CH}_{2}$ ), the mobility of the antioxidant group should favors a higher radical scavenging efficiency but, at the same time, the tertiary carbons are the most exposed to radical generation. As a consequence, the mid-length spacer with four $\mathrm{CH}_{2}$ could be considered as the better compromise between mobility of the phenolic group and steric protection of the main chain.

It is worth noticing that these results demonstrate, in any case, the very positive effect the polymeric additives have on the degradation onset of the polymeric matrix, retarding the thermo-oxidative sequence of reactions. The fact that neat LDPE and LDPE added with BHA have similar overall degradative behavior can be ascribed to the loss of the low molecular weight additive, which can occur during preparation of the film specimen by compression molding (at $130^{\circ} \mathrm{C}$ ) and/or during the TGA heating run by diffusion of $\mathrm{BHA}$ toward the
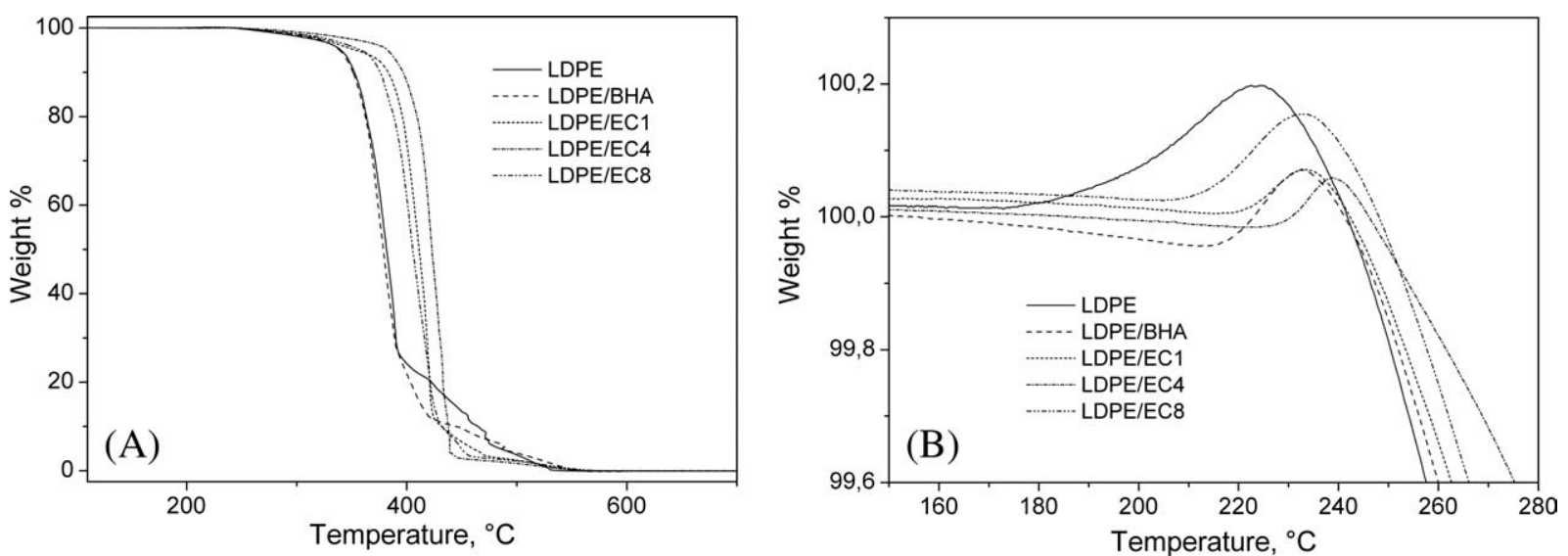

Figure 2 Dynamic TGA curves under $\mathrm{O}_{2}$ (heating rate $20^{\circ} \mathrm{C} / \mathrm{min}$ ) of LDPE blends containing the polymeric antioxidants. Neat LDPE and LDPE containing an equivalent amount of BHA are also reported for comparison. (A) Whole explored temperature range; (B) expansion of the $\mathrm{O}_{2}$ uptake region. 


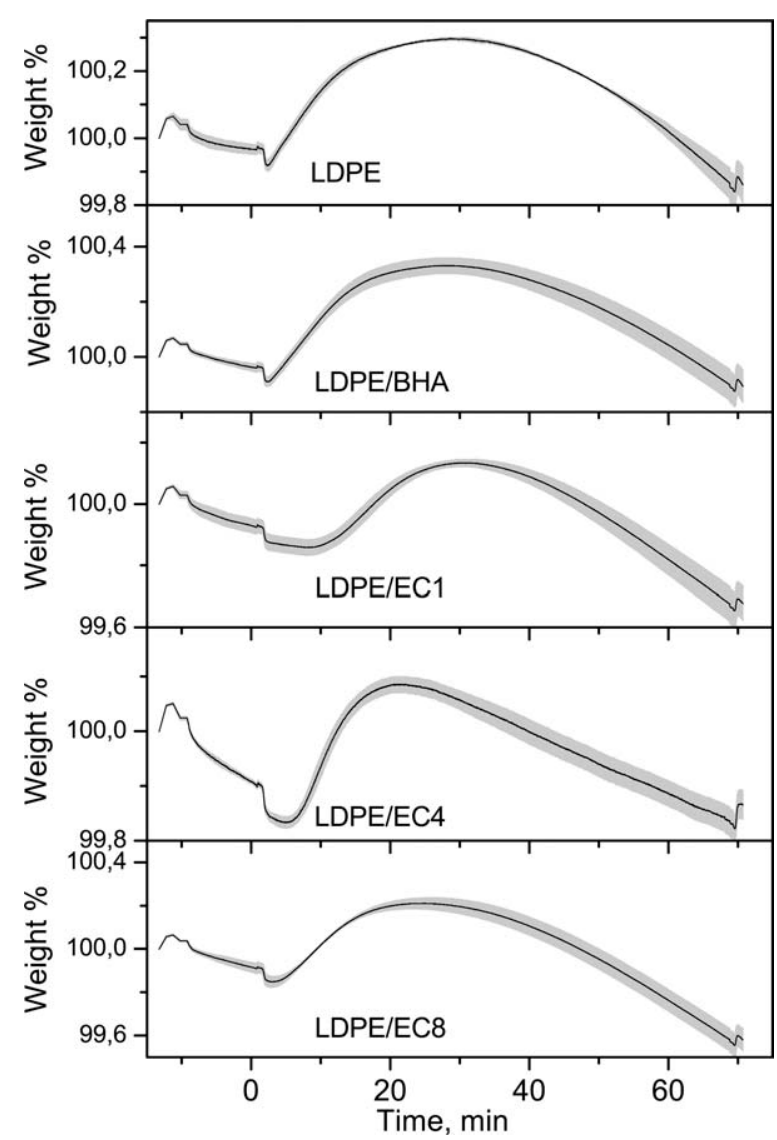

Figure 3 Isothermal TGA curves under $\mathrm{O}_{2}\left(T=180^{\circ} \mathrm{C}\right)$ of LDPE blends containing the polymeric antioxidants. Neat LDPE and LDPE containing BHA are also reported for comparison.

specimen surface and its subsequent evaporation. This assumption was also verified by Tochacek who measured significant weight losses of different stabilizers in polyethylene samples during the exposure at elevated temperatures due to their volatilization. ${ }^{25}$ Moreover, all this implies that, since the investigated polymeric additives cannot, in principle, be released from the polymer matrix, the usual practice of overcharging plastics with antioxidants to prevent their loss during compounding or transformation processes can be avoided, or at least reduced, by following the approach here proposed.

\section{Isothermal TGA}

Further TGA experiments under $\mathrm{O}_{2}$ atmosphere were carried out on film samples in isothermal conditions. The chosen temperature, $180^{\circ} \mathrm{C}$, allowed exploring the behavior of the novel polymeric antioxidant additives in thermal conditions mimicking those normally applied in the industry during processing of the polyolefinic materials.

First of all, reproducibility of the experimental method was tested conducting at least four different measurements for each sample; in Figure 3 the mean curve and the related error band are reported for each examined sample. Results show that, notwithstanding the very low weight range explored in these experiments (around $0.3 \%$-i.e., about $10 \mu \mathrm{g}$ ), data are very reliable.

In Figure 4, the abovementioned isothermal TGA curves are set on the same plot to compare the behavior of the different samples, each of them containing $500 \mathrm{ppm}$ of the antioxidant species. One can appreciate that for both neat LDPE and its blend with BHA, the degradation process starts as soon as the oxygen gas is introduced in the instrument furnace. This happens because, at the imposed temperature $\left(180^{\circ} \mathrm{C}\right), \mathrm{BHA}$ additive seems to be no longer present in sufficient amount within the polyethylene matrix.

On the contrary, and as desired, samples containing the polymeric additives exhibit a certain induction time before oxygen reacts with the polymer, starting the degradation process. Differently from what observed for the TGA experiments carried out in dynamic mode, in the adopted isothermal oxidative conditions the better result is obtained for the sample LDPE/EC1 with the shortest spacer between the polymer backbone and the antioxidant moiety, being in this case the time before the $\mathrm{O}_{2}$ uptake starts of about $10 \mathrm{~min}$. Thus, in this case the "steric factor," that is the protection of the tertiary carbon on the polymer backbone by the encumbering phenol moiety, seems to prevail on the mobility of the antioxidant moiety.

Again, it is worth noticing that, in any case, the induction times obtained, even for the blends containing the polymeric antioxidant with the worst response (LDPE/EC8), lie in a timespan comparable and even longer than the normal residence time of a polymer in an extruder during compounding or production processes. This can be considered as a

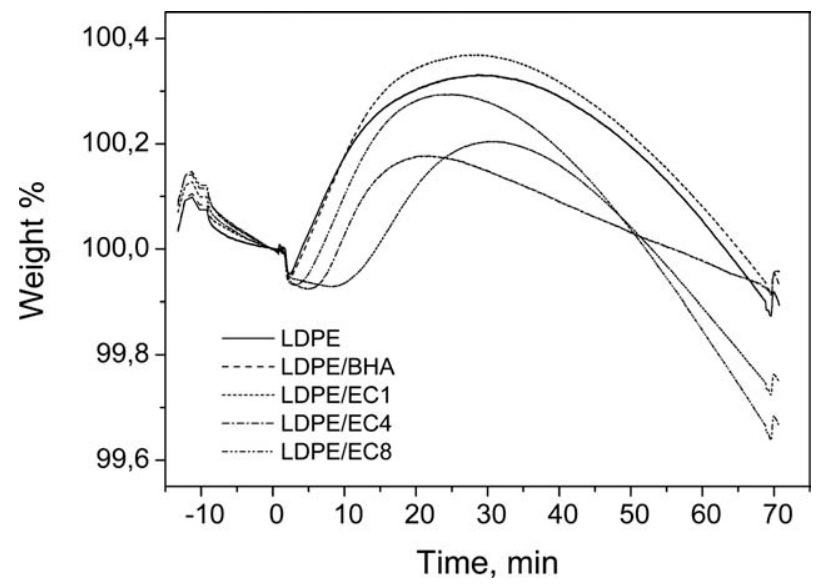

Figure 4 Comparison among the isothermal TGA curves shown in Figure 3. 


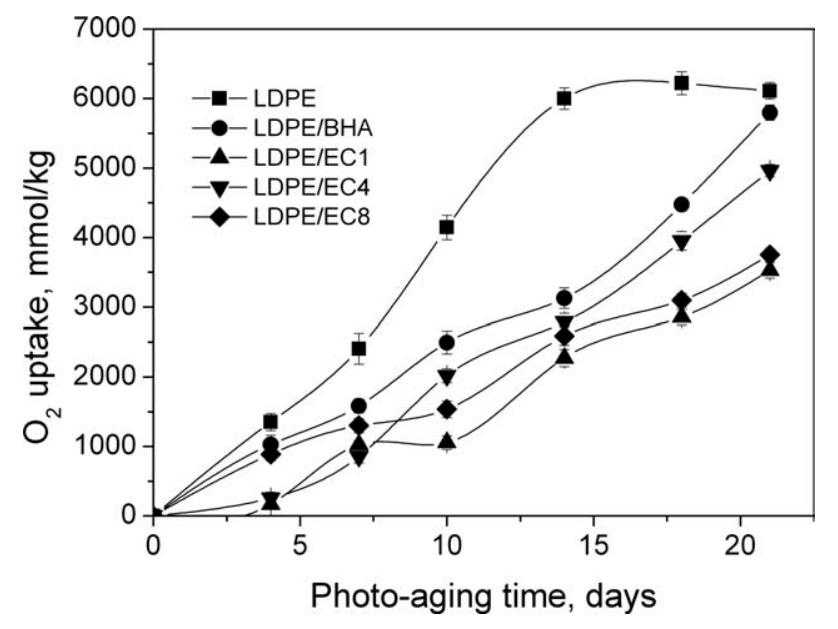

Figure 5 Oxygen uptake as a function of the photo-aging time for LDPE blends containing the polymeric antioxidants. Neat LDPE and LDPE containing an equivalent amount of BHA are also reported for comparison.

double advantage: the polymeric additive cannot exude or evaporate from the matrix, while is capable of stabilizing the polymeric material, avoiding the formation of peroxides throughout the permanence at high temperature.

\section{Aging tests}

Experiments of artificially induced aging were conducted exposing the film specimens, sealed in an oxygen-rich atmosphere, to a sun-like lamp radiation at $50^{\circ} \mathrm{C}$ for 21 days, according to the description detailed in the experimental section. Oxygen consumption in the head space atmosphere as well as the related photo-oxidative chemical modification of the LDPE samples was followed with time.

The action of an antioxidant additive may be detected in the induction stage and in the propagation step also by the evaluation of oxygen consumption. The higher the stabilization efficiency, the longer the oxidation time and the lower the oxidation rate. ${ }^{26}$

Figure 5 presents the dependence of oxygen uptake on photo-aging time for LDPE free of antioxidant, added with the traditional BHA and containing the polymeric additives. It can be observed that the neat LDPE sample exhibits the highest oxidation rate since the early stage of the experiment. Interestingly, among the antioxidant-containing samples, those with EC1 and EC4 show an induction period of more than 4 days. Sample with the EC8 polymeric additive initially presents a rate of oxidation similar to that of the LDPE film containing BHA, but on increasing the photo-exposition time the oxidation rate slows down and becomes comparable with those of the samples containing the polymeric additives with the shorter methylene spacers.
Photo-aging under oxidative conditions leads to notable modifications in the IR spectra of the exposed samples. In the case of polyethylene, the carbonyl groups accounted for the most of the oxidation products. For this reason, the concentration of carbonyl groups can be used to monitor the progress of degradation. In particular, the carbonyl absorption is composed of different overlapping bands corresponding to the $\mathrm{C}=\mathrm{O}$ stretching in acids (ca. 1712 $\mathrm{cm}^{-1}$ ), ketones (ca. $1723 \mathrm{~cm}^{-1}$ ), aldehydes (ca. 1730 $\mathrm{cm}^{-1}$ ), and lactones (ca. $1780 \mathrm{~cm}^{-1}$ ). In the present case, carboxylic acids, responsible for the maximum at $1714 \mathrm{~cm}^{-1}$, resulted to be the main oxidation products in all the tested samples.

To minimize errors from sample thickness, the $2019 \mathrm{~cm}^{-1}$ peak area $\left(A_{2019}\right)$, which is the combination of the absorbance at 1300 and $720 \mathrm{~cm}^{-1}$, due to bending and wagging of $\mathrm{CH}_{2}$ of polyethylene respectively, was selected as internal reference. ${ }^{19}$ The peak areas related to the stretching of carbonyl $\left(A_{\mathrm{C}=\mathrm{O}}\right)$, vinyl $\left(A_{\mathrm{C}=\mathrm{C}}\right)$, and hydroxyl $\left(A_{\mathrm{OH}}\right)$ groups were determined in the range of 1800-1670, 16601600 , and $3500-3150 \mathrm{~cm}^{-1}$, respectively. The corresponding carbonyl (CI), vinyl (VI), and hydroxyl (HI) indexes were calculated as follows ${ }^{19}$ :

$$
\begin{aligned}
& \mathrm{CI}=A_{\mathrm{C}=\mathrm{O}} / A_{2019}-\mathrm{CI}_{0} \\
& \mathrm{VI}=A_{\mathrm{C}=\mathrm{C}} / A_{2019}-\mathrm{VI}_{0} \\
& \mathrm{HI}=A_{\mathrm{OH}} / A_{2019}-\mathrm{HI}_{0}
\end{aligned}
$$

where $\mathrm{CI}_{0}, \mathrm{VI}_{0}$, and $\mathrm{HI}_{0}$ represent the $\mathrm{CI}, \mathrm{VI}$, and $\mathrm{HI}$ values before the aging experiment.

The changes in carbonyl absorbance are shown in Figure 6(A). It is evident that LDPE sample that does not contain any antioxidant shows the highest level of carbonyl formation. On the contrary, in the first stage of exposition (less than 5 days), LDPE/ EC1 and LDPE/EC4 samples offer a high protection against photo-oxidative degradation; even though, when the storage time is prolonged, the rate of carbonyl formation of those sample increase, reaching the same final values obtained for the other samples.

Similarly, during the first period of exposition (510 days) the increase in the formation of hydroxyl [Fig. 6(B)] and vinyl groups [Fig. 6(C)] was lower for the samples containing the EC1 and EC4 polymeric antioxidants, even if for longer exposition the indexes reach values comparable with those of the sample containing the traditional BHA.

Both thermo- and photo-oxidative studies highlighted that the EC8 polymeric additive seems to offer a lower protection to the LDPE matrix, if compared with EC1 and EC4 analogs. This, as already stated, may be ascribed to the fact that in the case of EC8, the longer methylenic spacer and thus the larger distance between the phenolic moiety and the 


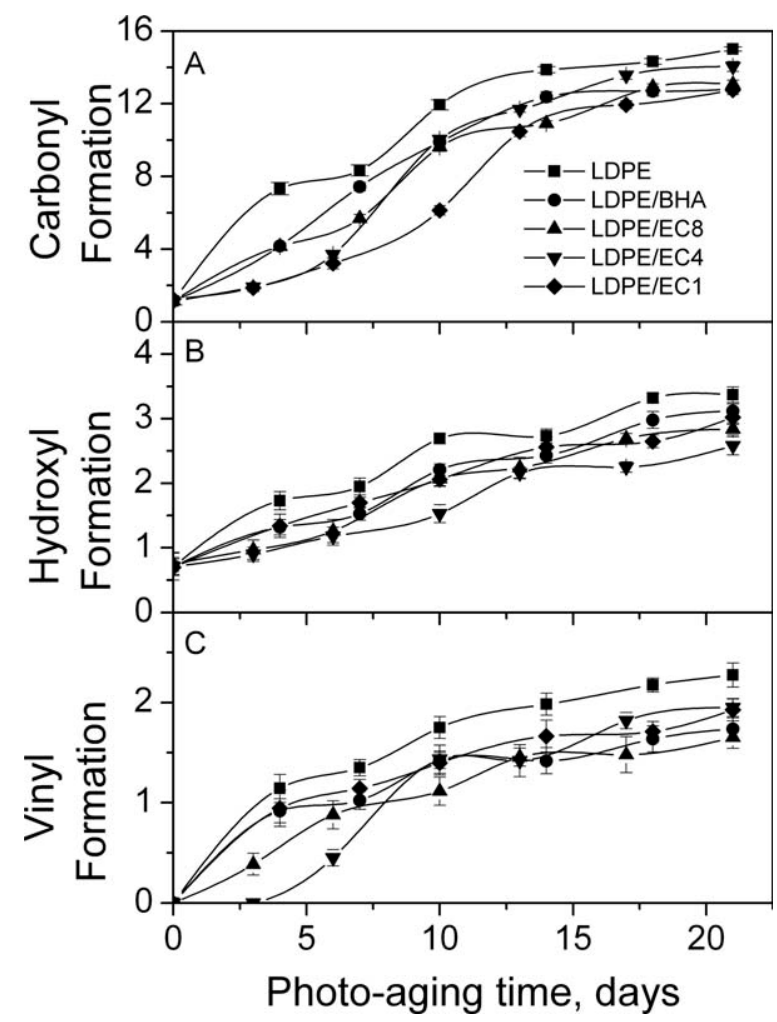

Figure 6 Evolution of (A) carbonyl, (B) hydroxyl, and (C) vinyl indexes upon photo-aging for LDPE blends containing the polymeric antioxidants. Neat LDPE and LDPE containing an equivalent amount of BHA are also reported for comparison.

polymer backbone, result in a reduced steric protection of the branching point brought about by the bulky antioxidant moiety itself.

\section{Specific migration test}

In the European Union, plastic additives and monomers used as food contact materials must fulfill strict requirements in terms of maximum acceptable migration threshold. ${ }^{27}$ These regulations are intended as safety measures for consumer protection, and the migration limits are based on toxicological assessment of the various substances. ${ }^{28}$

Taking into account the careful ${ }^{13} \mathrm{C}-\mathrm{NMR}$ analysis previously performed on the ECn copolymers, that completely excluded the presence of any trace of unreacted comonomer, ${ }^{17}$ here the attention was focused on the release of low molecular weight substances containing the aromatic residue typical of BHA. Indeed, such species could be potentially formed during melt-blending and film-forming by compression molding via degradation of the methylenic chain spacer.

On this basis, the film specimens were subjected to a specific migration test by using a food-simulating liquid following an European Union migration test protocol. $^{20}$ The potential release was evaluated by film immersion in iso-octane as fatty food simulant and subsequent analyses of the extraction residue by means of GC-MS. The ions used to identify and quantitatively determine the presence of species deriving from the antioxidant moiety were 137, 165, $180 \mathrm{~m} / \mathrm{z}$, which were selected since they are typical of BHA fragmentation. In this preliminary migration test, we intended to demonstrate that such fragments containing the aromatic ring originating from the BHA moiety were not present in the simulants. Indeed, a migration of BHA equal to $16 \pm 3 \mathrm{ppm}$ was measured in the LDPE film stabilized with such low molecular weight antioxidant. On the other hand, the GC-MS analysis of extraction residues obtained from ECn containing films did not show any species containing the abovementioned fragments, indicating that the covalently bonded antioxidant groups are not released in the polymer matrix. Moreover, these data suggest that the aliphatic tails binding the antioxidant aromatic group to the polymer chain are not fast-track sites for the thermo-oxidative attack and consequently do not represent a risk of release.

\section{CONCLUSIONS}

In this work, LDPE-based blends were formulated and prepared by means of a simple melt-blending technique by adding an antioxidant-free commercial LDPE matrix with novel highly efficient antioxidants. The latter were random copolymers of ethylene and a defined amount of an olefin bearing a covalently bonded BHA analog, placed at different distances from the polymer backbone. The higher compatibility of these polymeric stabilizers with polyethylene with respect to conventional low molecular weight additives guaranteed their uniform distribution in the polymer matrix.

Thermo-oxidative stability tests carried out under oxygen atmosphere on films prepared by compression molding showed a notably positive effect of the polymeric antioxidants, with $\mathrm{O}_{2}$ uptake onsets and subsequent thermo-oxidative degradation processes shifted at temperatures higher of $40-50^{\circ} \mathrm{C}$ with respect to neat or BHA-added LDPE samples. At the same time, artificial aging tests carried out on films under photo-oxidative conditions showed that the macromolecular antioxidants exert a protection against photo-oxidation, comparable or better than that offered by traditional low molecular weight additives. Last but not least, migration tests demonstrated the absence into a contact food simulant of any trace of products containing the antioxidant moiety, confirming the desired nonreleasing character of the polymeric antioxidants under investigation. 
The overall results show that exploitation of these novel polymeric antioxidants in melt-blending with cheap commercial polyolefin materials is possible, avoiding, as a matter of fact, all drawbacks due to migration of antioxidant additives in the packed food. Because of the versatility of metallocene-based catalysis, differently structured comonomers with a variety of possible functionalities specifically destined to protect special packages are currently under investigation in our laboratories.

This research was carried out in the framework of the CARIPLO Bank Foundation projects "Food Packaging: Polymeric Additives with a Low Diffusion Coefficient and Low Contamination Risk" and "Polymeric Additives with Covalently Bonded Stabilizers (PACk-BOSs): Design and Preparation of Lasting Polyolefin Films with No Risk of Food Contamination and Degradation."

\section{References}

1. Halliwell, B.; Gutteridge, J. M. C. Free Radicals in Biology and Medicine, 3rd ed.; Oxford Science Publications, Oxford University Press: London, 1998 and references cited therein.

2. Al-Malaika, S. In Comprehensive Polymer Science; Allen, G., Bevington, J. C., Eds.; (Eastwood, G. C., Ledwith, A., Russo, S., Sigwalt, P., Vol. Eds.); Pergamon Press: New York, 1989; Vol.6, p 539.

3. Pocas, M. F.; Hogg, T. Trends Food Sci Technol 2007, 18, 219.

4. Kuczowsky, J. A.; Gillick, J. G. Rubber Chem Technol 1984, 57, 621 and references therein.

5. Starnes, W. H., Jr.; Patton, T. L. Esso Research and Engineering Co. U.S. Pat.3,526,668 (1970).

6. Starnes, W. H., Jr.; Patton, T. L. Esso Research and Engineering Co. U.S. Pat.3,635,886 (1972).

7. Parker, D. K. Goodyear Tire and Rubber Company. U.S. Pat.4,366,331 (1982).
8. Starnes, W. H., Jr. Esso Research and Engineering Co. U.S. Pat.3,635,885 (1972).

9. Starnes, W. H., Jr. Esso Research and Engineering Co. U.S. Pat.3,644,539 (1972).

10. Starnes, W. H., Jr. Esso Research and Engineering Co. U.S. Pat.3,660,505 (1972).

11. Patton, T. L.; Horeczy, J. T.; Brown, D. E. Esso Research and Engineering Co. U.S. Pat.3,477,991 (1969).

12. Iwata, T.; Sasaki, J.; Mitsui Petrochemical Co., Ltd. Can. Pat. 876,796 (1971).

13. Wilén, C.-E.; Auer, M.; Nasman J. H. Polymer 1992, 33, 5049.

14. Wilén, C.-E.; Nasman J. H. Macromolecules 1994, 27, 4051.

15. Wilén, C.-E.; Nasman J. H. Macromolecules 1996, 29, 8569.

16. Sacchi, M. C.; Cogliati, C.; Losio, S.; Stagnaro, P.; Menichetti, S.; Viglianisi, C. Macromol Symp 2008, 260, 21.

17. Menichetti, S.; Viglianisi, C.; Liguori, F.; Cogliati, C.; Boragno, L.; Stagnaro, P.; Losio, S.; Sacchi, M. C. J. Polym Sci Part A Polym Chem 2008, 46, 6393.

18. Gijsman, P.; Hennekens, J.; Tummers, D. Polym Degrad Stab 1993, 39, 225.

19. Yang, R.; Yu, J.; Liu, Y.; Wang, K. Polym Degrad Stab 2005, $88,333$.

20. Br Standard EN 13130-1. Materials and Articles in Contact with Foodstuffs-Plastics Substances Subject to Limitation, Part 1: Guide to Test Methods for the Specific Migration of Substances from Plastics to Foods and Food Simulants and the Determination of Substances in Plastics and the Selection of Conditions of Exposure to Food Simulants; Br Standard: London, 2004, p 1.

21. Lau, O.-W.; Wong, S.-K. J Chromatogr A 2000, 882, 255.

22. Heiserman, W. M.; Can, S. Z.; Walker, R. A.; Begley, T. H.; Limm, W. J Colloid Interface Sci 2007, 311, 587.

23. Linssen, J. P. H.; Reitsma, J. C. E.; Cozijnsen, J. L. Packag Technol Sci 1998, 11, 241.

24. Grob, K.; Pfenninger, S.; Pohl, W.; Laso, M.; Imhof, D.; Rieger, K. Food Control 2007, 18, 201.

25. Tochacek, J. Polym Degrad Stab 2004, 86, 385.

26. Zaharescu, T. Mat Res Innov 2001, 5, 35.

27. European Commission Directive 2002/72/EC on Food Contact Materials and its subsequent amendments. (Available at http: / /ec.europa.eu/food/food/chemicalsafety/foodcontact/ legisl_list_en.htm

28. Philo, M. R.; Jickells, S. M.; Damant, A. P.; Castle, L. J. Agric Food Chem 1994, 42, 1497. 